\title{
Dysregulated Interleukin 6 Expression Produces a Syndrome Resembling Castleman's Disease in Mice
}

Stephen J. Brandt, David M. Bodine, Cynthia E. Dunbar, and Arthur W. Nienhuis

Clinical Hematology Branch, National Heart, Lung, and Blood Institute, National Institutes of Health, Bethesda, Maryland 20892

\begin{abstract}
Interleukin 6 (IL-6) is an important regulator of the acute phase response, $T$ cell function, and terminal $B$ cell differentiation. Excessive or inappropriate production of this cytokine may be involved in a variety of autoimmune and neoplastic disorders. To investigate the consequences of dysregulated synthesis of IL-6 in vivo, a high-titer recombinant retroviral vector produced in $\psi-2$ packaging cells was used to introduce the coding sequences of murine IL-6 into mouse hematopoietic cells. Congenitally anemic $W / W^{v}$ mice reconstituted with bone marrow cells transduced with the retroviral vector developed a syndrome characterized by anemia, transient granulocytosis, hypoalbuminemia, and polyclonal hypergammaglobulinemia, with marked splenomegaly and peripheral lymphadenopathy. Extensive plasma cell infiltration of lymph nodes, spleen, liver, and lung was noted. The similarity of these findings to those of multicentric Castleman's disease, taken together with the observation that lymph nodes from these patients elaborate large amounts of this cytokine, suggest that the inappropriate synthesis of IL-6 has a primary role in the pathogenesis of this systemic lymphoproliferative disorder. (J. Clin. Invest. 1990. 86:592-599.) Key words: growth factor • gene transfer • plasma cells - hypergammaglobulinemia - lymphoproliferative disorder
\end{abstract}

\section{Introduction}

Interleukin 6 (IL-6) is a multifunctional cytokine believed to be important in host defense, particularly in the initial response to infection or injury (reviewed in reference 1). IL-6 induces the synthesis of acute phase proteins by hepatocytes (2-4), stimulates immunoglobulin synthesis by B cells $(5,6)$ and differentiation of cytotoxic $T$ cells $(7,8)$, and induces both pluripotential hematopoetic progenitor cells to enter the cell cycle (9) and more committed progenitors to differentiate into granulocytes and macrophages $(10,11)$. It is synthesized in response to a variety of stimuli, including viruses $(12,13)$ and other cytokines such as interleukin 1 and tumor necrosis factor $(14,15)$, and appears in circulation in a number of febrile illnesses (16-18).

There is considerable, although largely circumstantial, evidence implicating abnormal expression of IL-6 in a variety of

Presented in part at the 31st Annual Meeting of the American Society of Hematology, 1-5 December, 1989, Atlanta, GA and published in abstract form.

Address reprint requests to Dr. Brandt, Clinical Hematology Branch, National Heart, Lung, and Blood Institute, NIH, Building 10, Room 7C-103, Bethesda, MD 20892.

Received for publication 30 January 1990.

The Journal of Clinical Investigation, Inc.

Volume 86, August 1990, 592-599 disease states. IL-6 may function as an autocrine or paracrine growth factor in multiple myeloma $(19,20)$, myeloid leukemia (21), lymphoma (22), and renal cell carcinoma (23), and in nonneoplastic disorders such as psoriasis (24) and mesangial proliferative glomerulonephritis (25). Synthesis of IL-6 by rheumatoid synovium (26-28), by the germinal centers of hyperplastic lymph nodes in Castleman's disease (29), and by certain tumors (30) suggests it may also have a role in producing the fever, hypergammaglobulinemia, and changes in acute phase proteins associated with these disorders.

To investigate the consequences of dysregulated synthesis of IL-6 in vivo, we constructed a high-titer retroviral vector bearing the murine IL- 6 coding sequences and introduced the gene into hematopoietic cells of mice. Congenitally anemic $\mathrm{W} / \mathrm{W}^{\mathrm{v}}$ mice transplanted with retrovirus-infected bone marrow cells developed a syndrome that closely resembles multicentric Castleman's disease.

\section{Methods}

Animals and cells. $\mathrm{WBB} 6 \mathrm{~F} 1 \mathrm{~W} / \mathrm{W}^{\mathrm{v}}$ and $\mathrm{C} 57 \mathrm{BL} / 6 \mathrm{~J}$ mice were purchased from the Jackson Laboratory (Bar Harbor, ME). The IL-6-dependent murine plasmacytoma cell line T1165 (31) was provided by Dr. Richard Nordan, and the $\psi-2$ packaging line (32) was obtained from Dr. Richard Mulligan. The PA317 packaging cell line (33) was obtained from the American Type Culture Collection (Rockville, $M D$ ).

Construction of N2-IL6 vector and retrovirus producer line. The 1.6-kb Pst I-Nde I fragment of pCD-mIL6 (11) was ligated with the 2.7-kb Pst I-Nde I fragment of pCD-IL3 (34). The Xho I-Ssp I fragment of the resulting plasmid containing murine IL-6 coding sequences preceded by two SV40 splice acceptor sequences was subcloned into the polylinker of a modified pUC plasmid. A 1.1-kb Xho I-Sal I fragment of this intermediate construct was then subcloned into the Xho I cloning site of a plasmid containing the $\mathrm{N} 2$ retroviral vector (35) and the correct orientation selected. The resulting retroviral vector was designated N2-IL6 (Fig. 1).

$\psi$-2 packaging cells were transfected using the calcium phosphate method (36), and individual neomycin resistant $\left(n^{2} o^{R}\right)^{1}$ clones were expanded after selection for $10 \mathrm{~d}$ in the neomycin analogue $\mathrm{G} 418$ at a concentration of $0.4 \mathrm{mg} / \mathrm{ml}$ active drug. To achieve a higher titer producer line, supernatant from the clone with the highest titer obtained by direct transfection $\left(3 \times 10^{6} \mathrm{neo}^{\mathrm{R}} \mathrm{U} / \mathrm{ml}\right)$ was used to infect the PA317 amphotropic packaging cell line. $48 \mathrm{~h}$ later, filtered supernatant was applied to $\psi$-2 cells and individual neomycin-resistant clones were selected in G418 as described. One ecotropic producer clone with a titer of $4 \times 10^{7} \mathrm{neo}^{\mathrm{R}} \mathrm{U} / \mathrm{ml}$ was used for all gene transfer experiments. Helper virus was detected only in undiluted supernatant ( 2 plaqueforming units/ml) using an S+ L- assay (37). A $\psi$-2 line producing a comparable titer of $\mathrm{N} 2$ virus was used for controls.

Retrovirus infection of bone marrow. Bone marrow was flushed from the hind limbs of C57BL/6J donor mice $48 \mathrm{~h}$ after intravenous injection with $150 \mathrm{mg} / \mathrm{kg} 5$-fluorouracil. The cells were pooled, washed, and placed on plastic plates (Sarstedt, Princeton, NJ) in Dulbecco's modified Eagle's medium containing 15\% WEHI-conditioned

1. Abbreviations used in this paper: $\mathrm{neo}^{\mathrm{R}}$, neomycin resistant. 

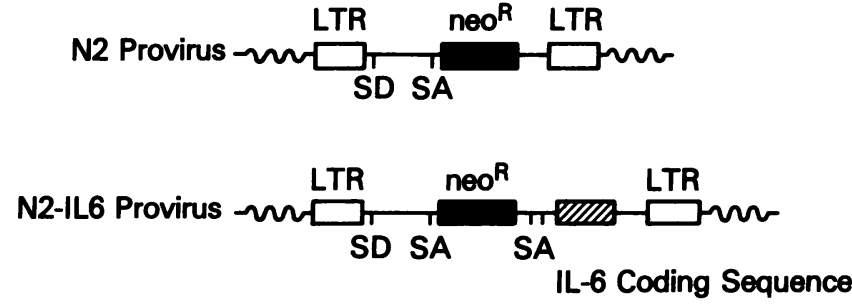

Figure 1. Structures of proviral or integrated form of N2 and N2-IL6 retroviruses. SD and SA denote splice donor and splice acceptor sequences, respectively, and neo $o^{R}$ (shaded box) represents neomycin phosphotransferase coding sequences. The IL-6 coding sequences (hatched box) are preceded by two SV40-derived splice acceptor sites.

medium as a source of murine IL-3, 10\% heat-inactivated fetal calf serum (Hyclone Laboratories), $0.3 \mathrm{~g} /$ liter glutamine, and antibiotics. In some experiments, murine IL- 6 was added in the form of COS cell-conditioned medium at a final concentration of $0.1 \% \mathrm{vol} / \mathrm{vol}(65$ $\mathrm{U} / \mathrm{ml}$ ). After $48 \mathrm{~h}$, marrow was collected from plates and co-cultured with subconfluent plates of producer cells in the above medium, to which was added $6 \mu \mathrm{g} / \mathrm{ml}$ polybrene. Bone marrow cells were collected after $72 \mathrm{~h}$, washed once with Hepes-buffered saline, and transplanted into $\mathrm{WBB} 6 \mathrm{~F} 1 \mathrm{~W} / \mathrm{W}^{\mathrm{v}}$ recipients by tail vein injection. Each mouse received between 0.5 and $1.0 \times 10^{6}$ cells.

IL-6 assay. IL-6 activity of serum and plasma samples was measured in a microproliferation assay using the factor-dependent plasmacytoma cell line T1165. T1165 cells in log phase were washed twice with RPMI 1640 medium containing 10\% heat-inactivated fetal calf serum and $5 \times 10^{-5} \mathrm{M} \beta$-mercaptoethanol, and $1 \times 10^{4}$ cells were mixed with the test sample in a total volume of $100 \mu$ l. Viable cells were counted after $48 \mathrm{~h}$ and activity expressed in units, with 1 unit defined as the dilution giving half-maximal growth.

Hematological analysis. Recipients were bled from the retroorbital plexus weekly or biweekly. Differential cell counts (100 cells) were performed on Wright's stained peripheral blood films. Hematocrit was determined after centrifugation of blood collected in heparinized microcapillary tubes. Hemocytometer platelet counts were made under phase microscopy after lysis of red cells with ammonium oxalate. Leukocyte counts were measured with a Coulter $\mathrm{Zm}$ particle counter (Coulter Instruments, Hialeah, FL). Hemoglobin phenotype was determined by cellulose acetate electrophoresis of peripheral blood as previously described (38).

Pathological analysis. Animals were sacrificed by cervical dislocation and organs fixed in $10 \%$ formaldehyde for subsequent histological analysis. Thin sections of paraffin-embedded tissues were stained with hematoxylin and eosin, Congo red, and Mallory stains. Cytospin preparations of bone marrow, lymph node, and spleen were stained with Wright's stain.

Immunoglobulin analysis. Cellulose acetate electrophoresis and immunoelectrophoresis of serum and plasma samples were performed according to manufacturer's instructions (Helena Laboratories, Beaumont, TX). Immunoglobulin levels were measured with a radial immunodiffusion kit using the diffusion times recommended by the manufacturer (The Binding Site, San Diego, CA). Antiserum to immunoglobulin subclasses was obtained from Caltag Laboratories (South San Francisco, CA) and The Binding Site.

Nucleic acid analysis. High molecular weight DNA was obtained from mouse organs by digestion overnight at $55^{\circ} \mathrm{C}$ in $50 \mathrm{mM}$ Tris (pH 7.4), $100 \mathrm{mM}$ EDTA, $100 \mathrm{mM}$ sodium chloride, $1 \% \mathrm{SDS}$, and $2 \mathrm{mg} / \mathrm{ml}$ proteinase K. DNA was ethanol precipitated after phenol and chloroform extractions and resuspended in $10 \mathrm{mM}$ Tris (pH 7.4), $1.0 \mathrm{mM}$ EDTA. Restriction endonuclease digestion with Sst I, Bgl II, or Eco R1, agarose gel electrophoresis, and Southern blot analysis were performed using standard techniques (39). A 0.6-kb Bgl II-Nco I fragment of pRSVneo was used to probe for proviral sequences, and a $0.7 \mathrm{~kb}$ $\mathrm{Xba}$ I-Eco R1 murine heavy chain joining probe was used to screen tissues for the presence of clonal immunoglobulin gene rearrangements. Total cellular RNA was obtained using the guanidine isothiocyanate/cesium chloride method (40), and Northern blot analysis was carried out as described (39) using a 0.6-kb Pst I-Bgl II fragment of the murine IL- 6 cDNA as probe. All probes were labeled with ${ }^{32} \mathrm{P}$ by random primer extension (41).

\section{Results}

Hematopoietic cells contain and express the IL-6 gene. The majority of pathological studies were performed on a group of $14 \mathrm{~W} / \mathrm{W}^{\mathrm{v}}$ recipients transplanted with donor bone marrow cells infected with the N2-IL6 retrovirus. Plasma immunoglobulin levels and IL-6 activity were measured in seven additional animals. Five animals transplanted with cells infected with the $\mathrm{N} 2$ retrovirus served as controls. 15 of the 21 animals (71\%) receiving bone marrow cocultured with the $\psi$-2 IL-6 producer line developed a syndrome characterized by anemia, leukocytosis, hypoalbuminemia, and polyclonal hypergammaglobulinemia. Two animals died within 4 wk of transplant and were not evaluable. A total of six animals with this syndrome resulting from either transplantation of retrovirus-infected donor cells or of bone marrow cells from affected animals were autopsied between 15 and 21 wk after transplant. Southern blot analysis of DNA from peripheral blood, bone marrow, and/or other organs verified integration of the N2-IL6 proviral genome in all.

Southern blot analysis was also used to study retroviral integration patterns. DNA from a variety of organs was digested with $\mathrm{Bgl}$ II, which cuts once within the integrated provirus and produces a unique junctional fragment for each viral integrant. To verify hematopoietic stem cell integration of the N2-IL6 virus, two primary animals were killed at $12 \mathrm{wk}$ or later and their bone marrow injected into secondary recipients. DNA obtained 12 wk or later from these animals was similarly analyzed. Two affected secondary recipients of bone marrow from the same primary animal showed an identical pattern in hematopoietic and lymphoid tissues, consistent with reconstitution with a stem cell containing four retroviral integrants (Fig. 2). Southern blot analysis of DNA from peripheral blood (not shown) and spleen (Fig. 2) of the primary animal revealed a more complex pattern, suggesting that more than one retrovirus-infected stem cell was contributing to hematopoiesis at the time it was killed.

Northern blot analysis revealed spliced retroviral transcripts of the expected lengths in RNA isolated from tissues infiltrated with plasma cells (Fig. 3). The 2.2-kb species from which IL-6 protein is translated was found in lower abundance than the full-length genomic and other major spliced transcript, as was noted with a similarly constructed retrovirus bearing the coding sequences for murine IL-3 (42). The level of retroviral RNA expression detected in Northern blot analysis correlated with the relative intensity of proviral bands in DNA analysis of corresponding tissues.

Using an assay for plasmacytoma growth factor activity, elevated levels of IL-6 were found in serum and plasma of animals receiving marrow infected with the N2-IL6 virus. Serum IL-6 activity ranged between 400 and $3,200 \mathrm{U} / \mathrm{ml}$ in animals studied $8 \mathrm{wk}$ after transplant. This activity was completely inhibited by a rabbit polyclonal antiserum to murine IL-6 (data not shown). In contrast, IL-6 activity was not detected in any of the N2 controls. No direct relationship be- 


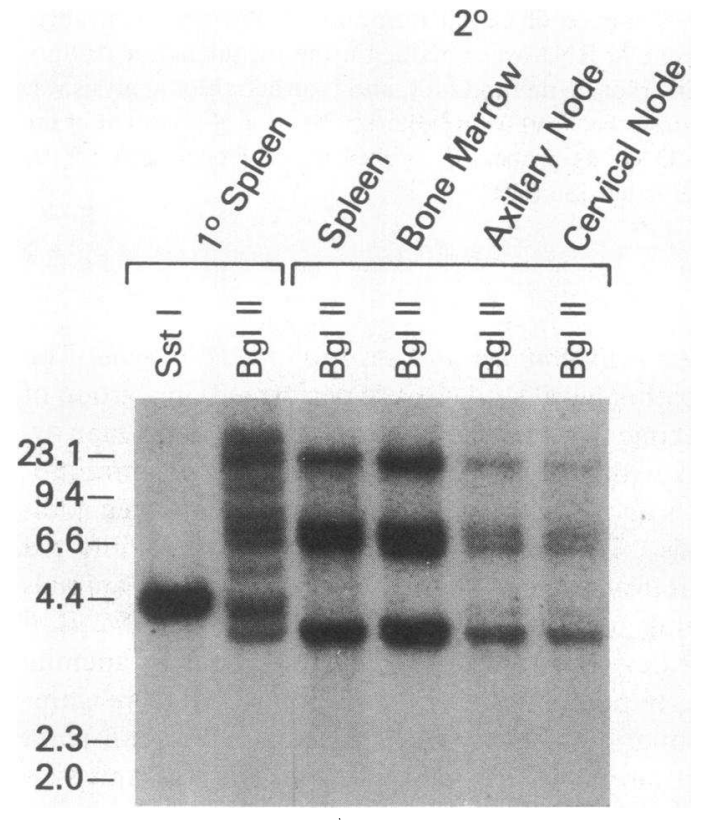

Figure 2. Southern blot analysis of proviral integration patterns. DNA from spleen of an affected animal and the indicated organs from a secondary recipient of bone marrow from this animal was digested with Sst I and Bgl II and subjected to Southern blot analysis using the 0.6-kb Bgl II-Nco I fragment of pRSVneo as a probe. Digestion with Sst I, which cuts within each long terminal repeat, gives a single band of the same size as the provirus. Bgl II cuts once within the provirus and gives a unique band for each proviral integrant. All tissues analyzed from this secondary recipient and another affected secondary recipient (not shown) contained four proviral integrants, with higher copy numbers seen in peripheral blood, bone marrow, and spleen than in lymph nodes and thymus. Additional proviral integrants were noted in spleen and peripheral blood of primary animal. Numbers represent sizes in kilobases of DNA markers.

tween circulating IL-6 activity and plasma IgG levels was noted.

IL-6 induces a polyclonal hypergammaglobulinemia with plasma cell hyperplasia. Cellulose acetate electrophoresis of plasma revealed a diffusely increased gamma globulin fraction, consistent with a polyclonal hypergammaglobulinemia, in the majority of animals transplanted with bone marrow cells infected with the N2-IL6 virus (Fig. $4 A$ ). Quantitative immunoglobulin measurements of plasma obtained $10 \mathrm{wk}$ after transplant showed the mean IgG level to be increased to $49,290 \pm 10,092$ from $5,190 \pm 1,037 \mathrm{mg} /$ liter (mean \pm SD), mean IgA level increased to $15,717 \pm 2,194$ from $5,880 \pm 495 \mathrm{mg} / \mathrm{liter}$, and mean IgM level increased to $456 \pm 133$ from $259 \pm 13 \mathrm{mg} /$ liter in IL-6 animals relative to concurrent N2 controls. Immunoelectrophoresis of plasma from one IL-6 animal demonstrated symmetrically increased precipitin arcs for the $\operatorname{IgG}_{1}$ and $\operatorname{IgG}_{2 \mathrm{~b}}$ fractions (Fig. $4 \mathrm{~B}$ ).

Postmortem examination revealed massive splenomegaly and peripheral lymph node enlargement. Multiple, enlarged cervical, axillary, subcutaneous, mesenteric, and inguinal nodes of up to $1 \mathrm{~cm}$ in size were seen, without significant mediastinal or retroperitoneal adenopathy. Histological analysis showed almost complete replacement of nodes by mature plasma cells; the sinuses were dilated and follicles atretic (Fig. 5). Marked expansion of the splenic red pulp by plasma cells

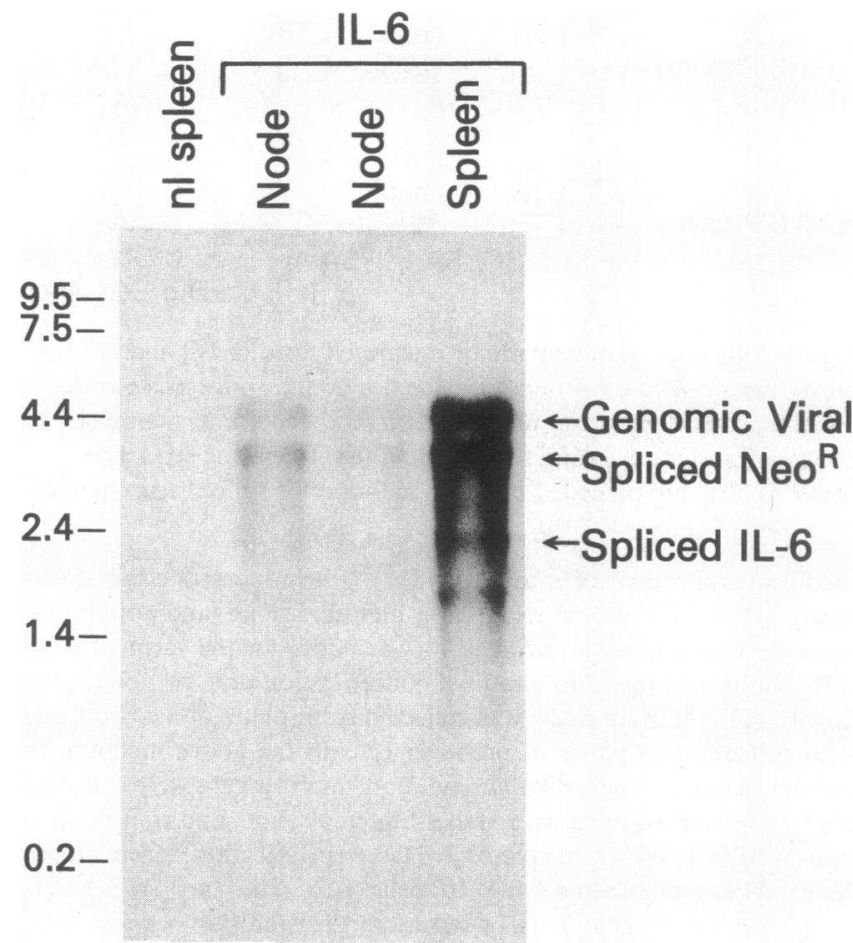

Figure 3. Expression of murine IL-6 mRNA in lymphoid tissues from $\mathrm{W} / \mathrm{W}^{\mathrm{v}}$ mouse transplanted with marrow infected with the N2-IL6 retrovirus. Total RNA ( $10 \mu \mathrm{g}$ per lane) extracted from normal spleen and from two hyperplastic nodes and spleen of IL-6 mouse 17 wk posttransplant was subjected to Northern blot analysis using the Pst I-Bgl II fragment of pCD-mIL6 as a probe. Numbers represent sizes in kilobases of RNA standards run in parallel. Major retroviral RNA species are labeled.

was also noted. Smaller numbers of plasma cells were also seen in kidney, portal zones of liver, and thymus. A pleomorphic infiltrate that included plasma cells and polymorphonuclear leukocytes was noted in the alveolar septae of lung.

Southern blot analysis was performed to verify the polyclonal nature of the plasma cell expansion in these animals. DNA was extracted from tissues rich in plasma cells, digested with Eco RI, and probed with a heavy chain joining region probe to detect immunoglobulin gene rearrangements. Only the $6.5-\mathrm{kb}$ germline band, with no apparent oligoclonal or monoclonal immunoglobulin gene rearrangements, was noted (Fig. 6), consistent with the results of plasma protein analysis demonstrating polyclonal hypergammaglobulinemia.

Hematological and systemic effects of IL-6. A striking elevation in leukocyte count developed in the majority of $W / W^{v}$ recipients within $3 \mathrm{wk}$ after transplantation of bone marrow cells infected with the N2-IL6 virus (Fig. 7) and in secondary recipients of bone marrow from affected animals. The majority of these cells were mature granulocytes, with no cells more immature than band forms noted. The leukocyte count reached a maximum after 6-8 $\mathrm{wk}$ and then subsequently decreased in animals surviving longer than $12 \mathrm{wk}$, although the differential continued to show a granulocytic predominance. These animals exhibited the hemoglobin phenotype of the donor and continued to have proviral sequences in circulating leukocytes, ruling out transient engraftment as an explanation for this transient granulocytosis (data not shown).

Animals receiving marrow transduced with the N2-IL6 

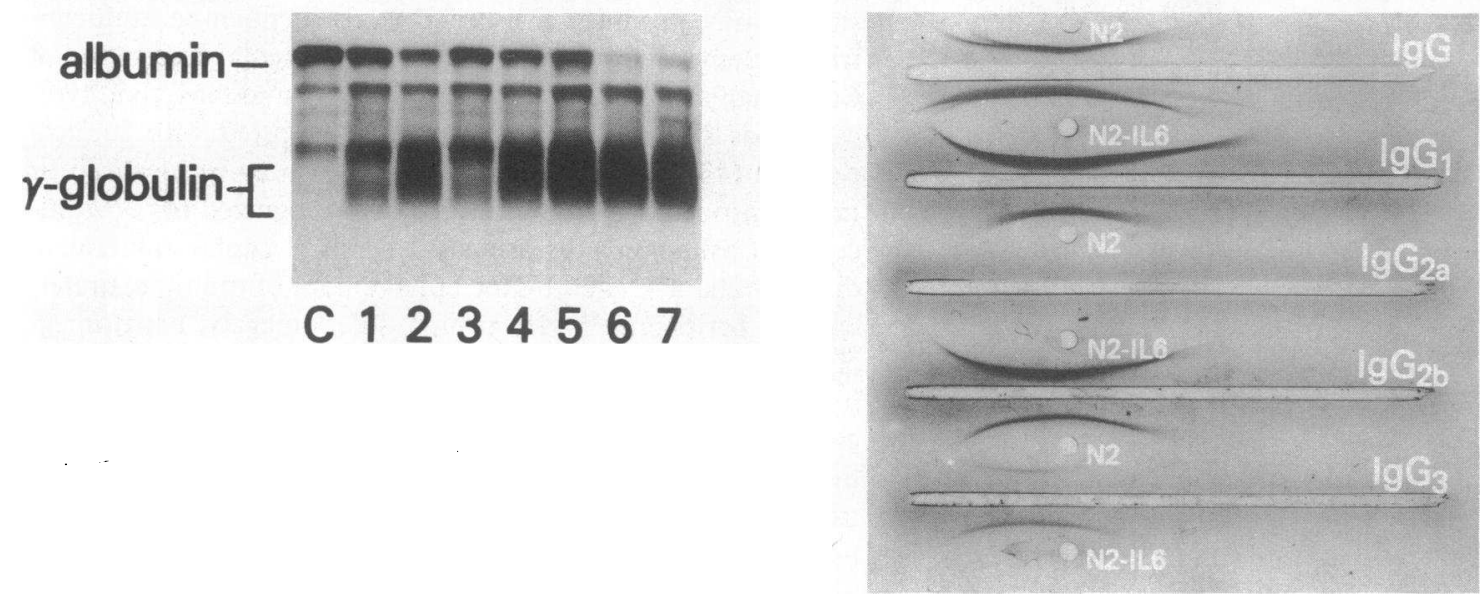

Figure 4. Immunoglobulin analysis of IL-6 mice. $(A)$ Cellulose acetate electrophoresis of plasma from control (lane $C$ ) and from individual animals 8 wk (lanes 1-4) and 14 wk (lanes 5-7) following transplantation with hematopoietic cells infected with the N2-IL6 virus. Marked hypoalbuminemia and polyclonal hypergammaglobulinemia are evident in plasma from animals 6 and 7 . (B) Immunoelectrophoresis of plasma obtained 8 wk posttransplant from an animal that received marrow infected with N2-IL6 virus and from concurrent N2 control. Symmetrically increased precipitin arcs are seen for the $\mathrm{IgG}_{1}$ and $\mathrm{IgG}_{2 b}$ subclasses in the IL-6 mouse.

virus also developed a hypochromic, microcytic anemia (Fig. 8). $10 \mathrm{wk}$ posttransplant, the mean hematocrit of one cohort of animals was $29 \%$ compared with $49 \%$ for a group of concurrent controls that received marrow infected with the parental $\mathrm{N} 2$ virus. The mean platelet counts of IL-6 animals were ap- proximately half those of a group of concurrent $\mathrm{N} 2$ controls for at least 4 wk posttransplant (data not shown).

A marked predominance of mature granulocytes, an increase in marrow macrophages, and occasional plasma cells were the principal findings in bone marrow. Megakaryocytes
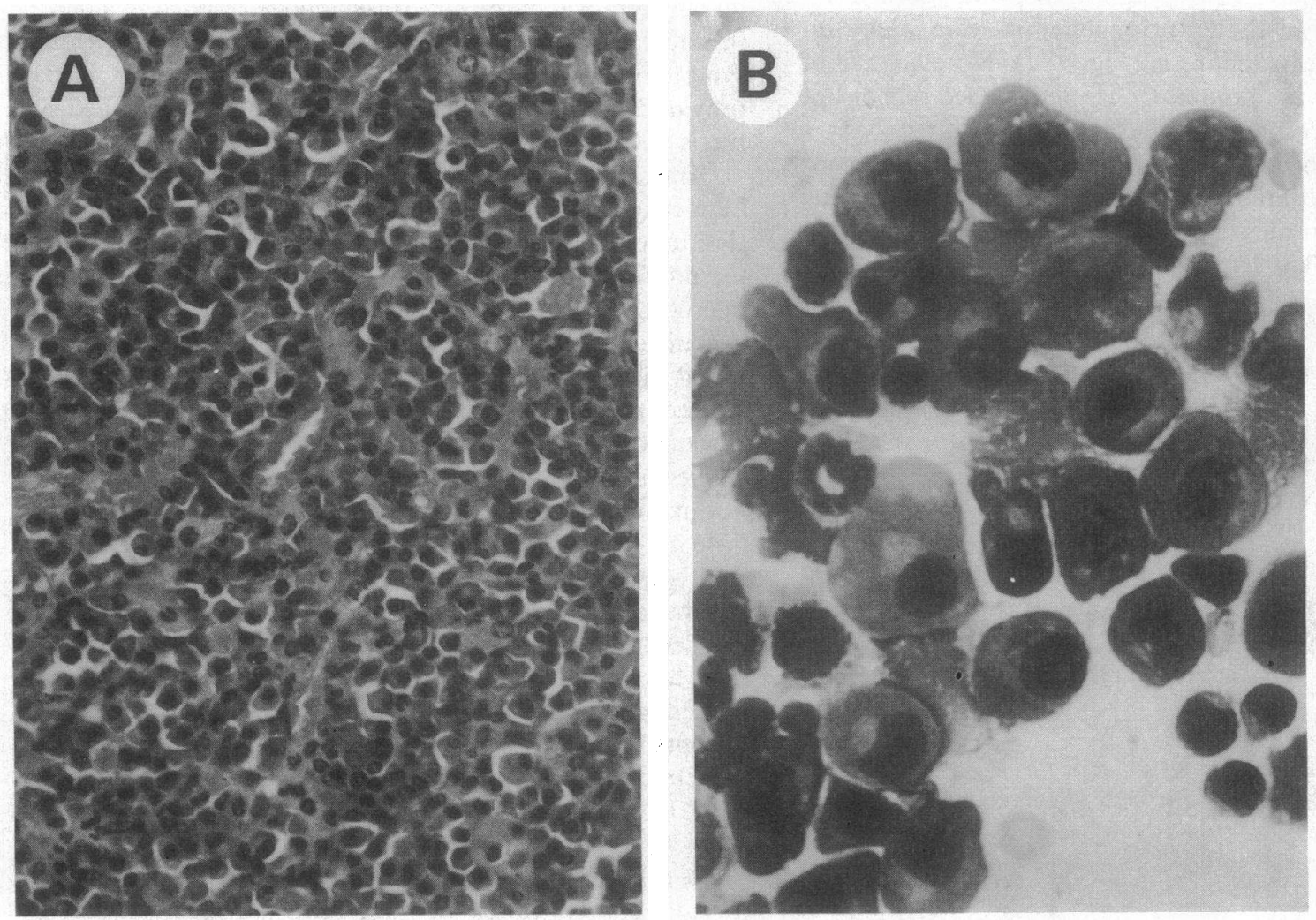

Figure 5. Lymph node histology of IL-6 mice. $(A)$ Hematoxylin and eosin-stained section of lymph node demonstrates diffuse infiltrate of plasma cells $(\times 125)$. $(B)$ Wright's stained cytospin preparation demonstrates typical morphology of mature plasma cells $(\times 312)$. Neutrophilic band with ring-shaped nucleus is also present. 


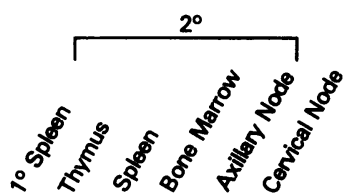

$23.1-$

9.4

$6.6-\longrightarrow \leftarrow$ Germline
Figure 6. Immunoglobulin gene rearrangement analysis. DNA from the indicated tissues from affected animals was digested with Eco RI and subjected to Southern blot analysis using a 0.7-kb Xba I-Eco RI fragment of the heavy chain joining region as a probe. No oligoclonal or monoclonal immunoglobulin gene rearrangements are apparent. The 6.5$\mathrm{kb}$ germline band is labeled. Numbers represent sizes in kilobases of 2.32.0 DNA markers.

appeared enlarged, although not increased in number, compared to controls. Focal infiltrates of polymorphonuclear leukocytes were noted also in lymphoid tissues in all animals studied, with occasional megakaryocytes seen in several nodes from one animal. Storage iron was present in bone marrow.

Production of IL- 6 appeared to have significant systemic effects. The majority of animals with the syndrome were inactive and many appeared dyspneic. Subcutaneous fat was markedly decreased, and most animals developed palpable splenomegaly. 5 of the first 14 IL-6 animals died within 15 wk and 3 had to be killed after 15-21 wk posttransplant. Marked hypoalbuminemia and hyperfibrinogenemia were noted on plasma protein electrophoresis (Fig. $4 A$ ). No evidence of amyloid deposits was found in Congo red-stained sections of bone marrow, liver, spleen, and heart.

In addition to the pathological changes produced in organs by plasma cell infiltration, glomerular enlargement, resulting from an increase in mesangial cells and matrix, was noted in stained sections of kidney (Fig. 9).

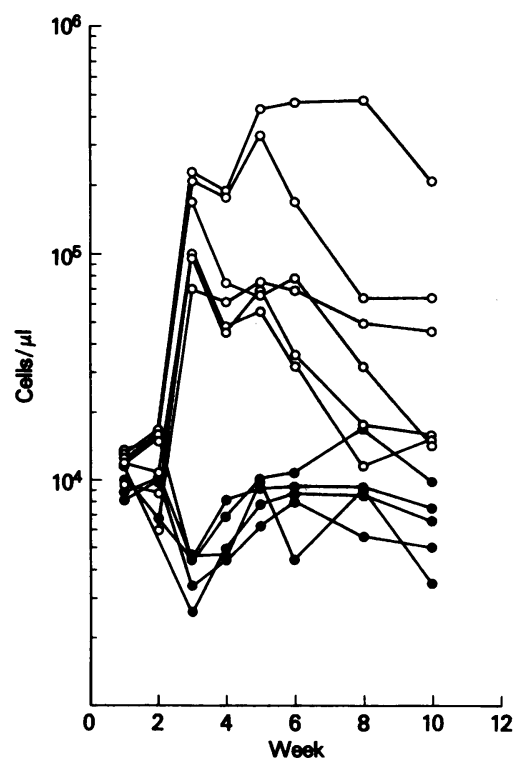

Figure 7. Serial leukocyte counts in $\mathrm{W} / \mathrm{W}^{\mathrm{v}}$ mice transplanted with hematopoietic cells infected with $\mathrm{N} 2(\bullet)$ or N2-IL6 (o) retrovirus. Each line represents data from a single animal.

\section{Discussion}

We have found that deliberate dysregulation of IL-6 expression in mice produces a disorder nearly identical to multicentric Castleman's disease in humans. The original description of Castleman's disease was of a solitary lymphoid mass that, typically, arises in the mediastinum and is cured with surgical excision (43). A plasma cell variant that may be localized or multicentric has been more recently recognized (44). Multicentric Castleman's disease is a systemic lymphoproliferative disorder characterized by the enlargement of multiple, preferentially peripheral, nodal groups, splenomegaly, hepatomegaly, and a variety of constitutional symptoms. Anemia and hypoalbuminemia were universal in one series (45), and polyclonal hypergammaglobulinemia has been noted in most patients. Thrombocytopenia is characteristic, and transient neutrophilia has also been observed. The diagnostic pathological findings are in lymph nodes and include diffuse plasmacytosis and prominent germinal centers, with preservation of nodal architecture (46). The clinical manifestations are often severe, and the disorder frequently proves fatal.

Multicentric Castleman's disease has been considered to be a hyperplastic lymphoproliferative disorder of an idiopathic nature (44). Recently, evidence for dysregulated IL-6 synthesis in both the localized and multicentric plasma cell forms has been provided by Kishimoto and colleagues (29). They reported that the lymph nodes from two patients conditioned media with biologically active IL-6 and, based on immunocytochemical studies, concluded that cells in the germinal center were the likely source. Elevated serum levels of IL-6 were measured in both patients, and, in one patient with localized disease, removal of the hyperplastic node resulted in a decline in circulating IL-6 levels followed by resolution of clinical symptoms and normalization of laboratory values. Our data provide a direct test of their hypothesis that dysregulated synthesis of IL- 6 has a causative role in this disorder.

The clinical, hematological, and gross pathological findings in mice transplanted with bone marrow cells infected with the IL-6 retrovirus are remarkably similar to those of patients with the multicentric form of Castleman's disease. Hypochromic, microcytic anemia, which may be severe, is a prominent feature in both. In one well-studied patient, the anemia was associated with hypoferremia, hypotransferrinemia, and increased storage iron in bone marrow (47), typical of the anemia of chronic disease. Hematocrit, red cell morphology, and iron studies subsequently normalized, as did the immunologic abnormalities, after excision of a mediastinal mass. Although we have not studied iron metabolism in the mice in detail, storage iron was present in bone marrow, and it is likely the anemia has the same pathogenesis.

Transient granulocytosis was also seen in the mice and may have resulted from both stimulation of pluripotential progenitors to enter the cell cycle and differentiation of progenitors committed to granulocyte and macrophage formation. In cell culture, IL-6 has been shown to act synergistically with IL-3 to support the proliferation of multipotential hematopoietic progenitors $(9,48)$ and to have granulocyte-macrophage colony-stimulating activity $(10,11)$. The enlargement of megakaryocytes noted in mice that had received marrow transduced with the N2-IL6 virus is also consistent with the cytokine's actions in vitro (49). Although brief administration of human IL- 6 has been reported to increase platelet counts in 

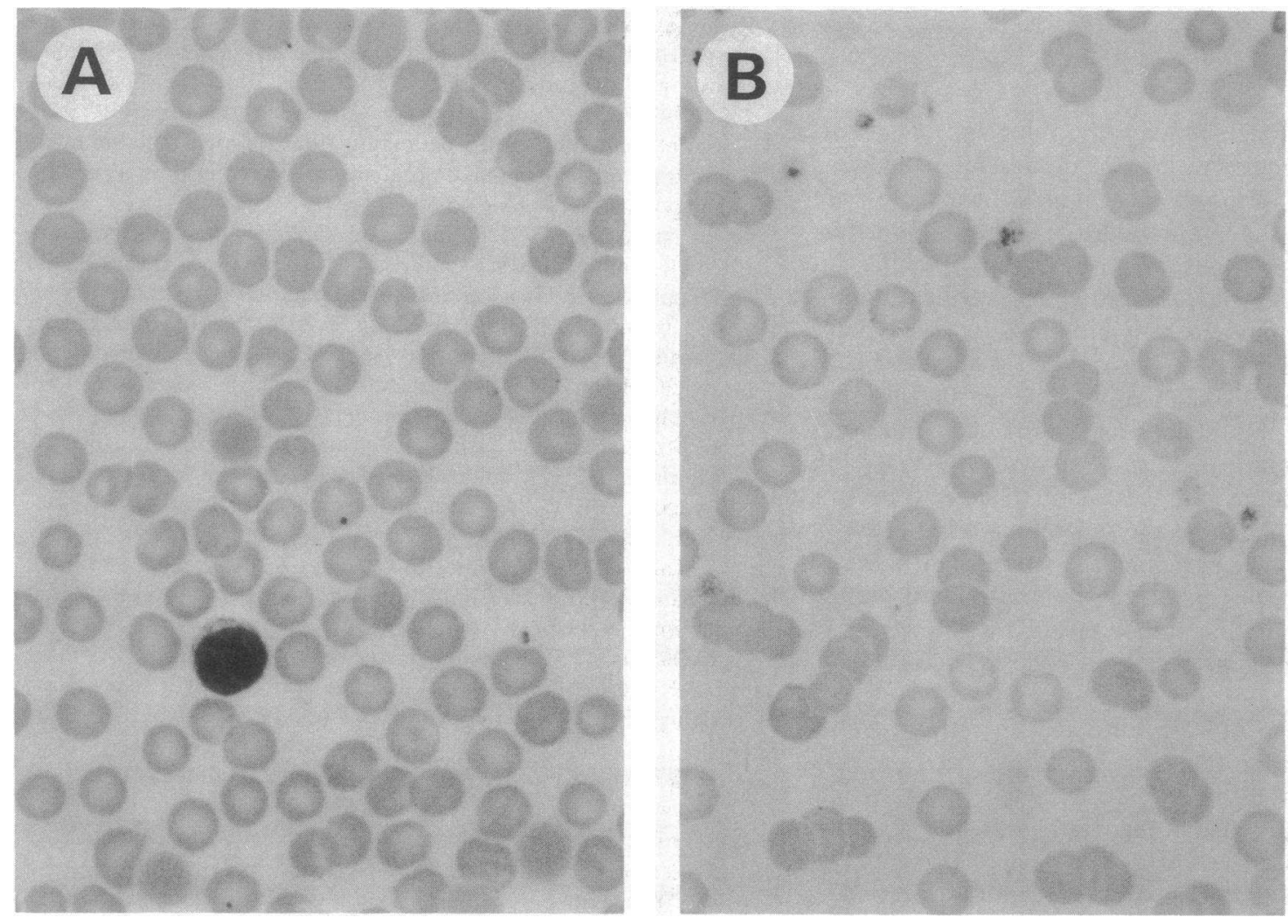

Figure 8. Representative Wright's stained blood films from W/Wv mice transplanted with hematopoietic cells infected with the $\mathrm{N} 2$ virus $(A)$ or N2-IL6 virus $(B)(\times 312)$. Animals receiving bone marrow transduced with the N2-IL6 virus developed hypochromic, microcytic anemia.
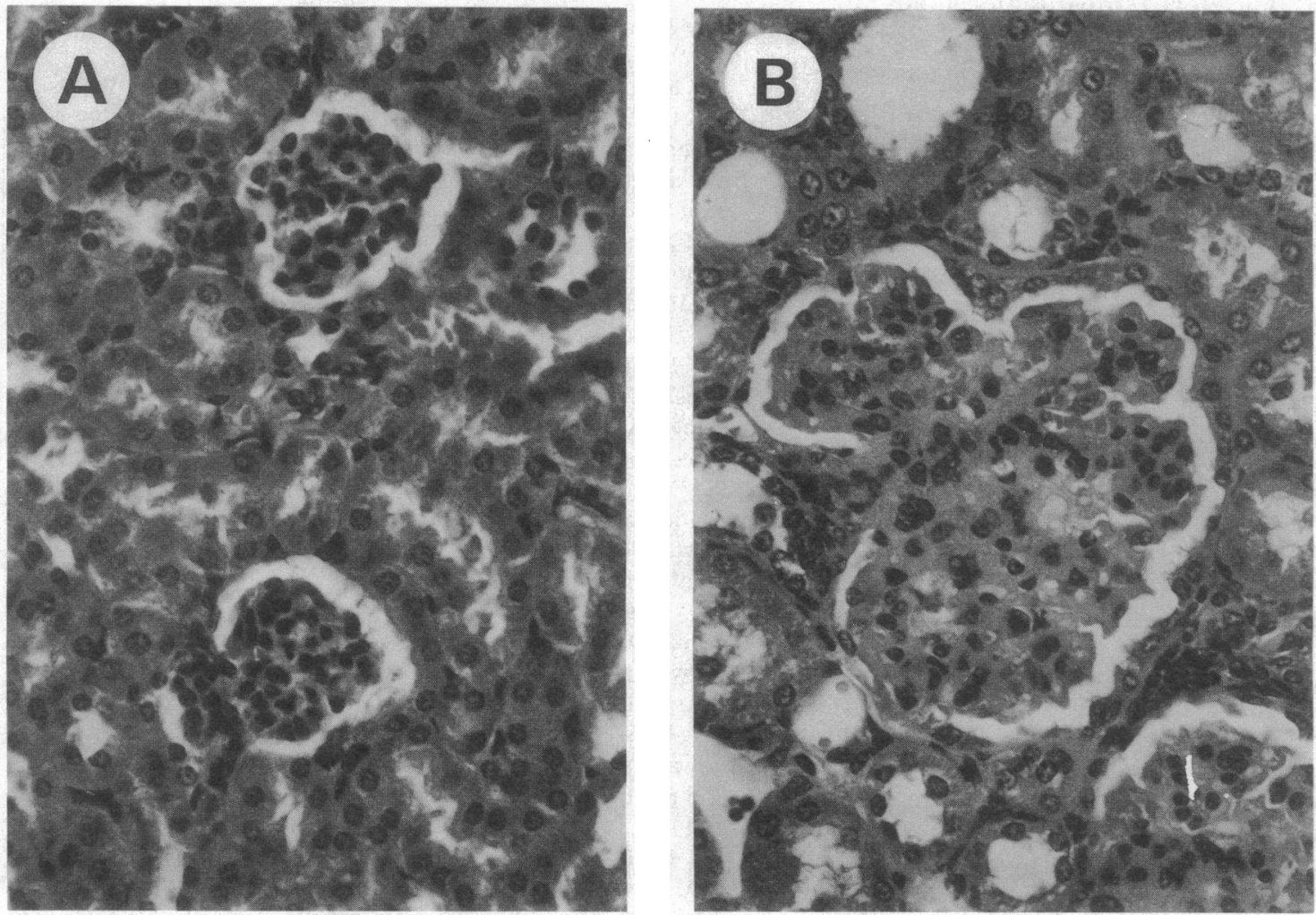

Figure 9. Hematoxylin and eosin-stained sections of kidney from mice receiving marrow infected with N2 $(A)$ or N2-IL6 virus $(B)(\times 125)$. Compared to the two normal glomeruli seen in the control mouse, glomerulus from IL-6 mouse is markedly enlarged from mesangial cell hyperplasia. 
mice (50), the IL-6 mice had lower platelet counts than concurrent controls, similar to patients with multicentric Castleman's disease, the majority of whom develop thrombocytopenia (45).

One notable difference between the mice and patients is that the germinal centers, which are prominent in patients with the plasma cell forms of Castleman's disease (46), are atretic in the hyperplastic lymph nodes of the mice. This may reflect the difference in the cell type secreting the cytokine. An abnormal cell in the germinal center, which may be a B lymphocyte (29), is the apparent source of IL-6 in Castleman's disease, while a bone marrow-derived cell that repopulates lymph nodes and spleen is likely responsible for the accumulation of plasma cells in these locations in the mice. The common retroviral integration pattern seen in DNA from both hematopoietic and lymphoid tissues and in different recipients of bone marrow from the same affected animal is indicative of retroviral infection of a hematopoietic stem cell. The presence of retroviral RNA species in organs infiltrated with plasma cells and extramedullary hematopoiesis in lymph nodes are in favor of local production of IL- 6 by a bone marrow-derived cell.

Findings similar to those resulting from retrovirus-mediated transfer of murine IL- 6 sequences have been noted in transgenic mice carrying the human IL-6 gene linked to the human immunoglobulin heavy chain enhancer (51), although no hematologic data were reported. These mice also developed polyclonal hypergammaglobulinemia and diffuse plasmacytosis involving lymph nodes, spleen, and thymus. It is evident from Southern blot analysis, however, that many of the plasma cells in the mice generated by retroviral gene transfer must not contain the introduced gene, in contrast to the situation that exists in the transgenic mice. The retrovirus model thus more closely simulates Castleman's disease, in which paracrine stimulation of B cell proliferation and differentiation is thought to occur.

Although not detected in either type of mice, clonal immunoglobulin gene rearrangements have been noted in some (52) but not other (53) patients with multicentric Castleman's disease. A proportion of these patients ultimately develop monoclonal lymphoproliferative disorders, including multiple myeloma (44), and it is possible that the altered expression of certain genes involved in cell growth is responsible for this neoplastic progression. Through the use of retrovirus-mediated gene transfer, it will be possible to test whether the enforced expression of IL-6 together with candidate genes such as c- $m y c$, believed to be important in the development of plasmacytomas in pristane-injected mice (54), is sufficient to produce a neoplastic disorder with a plasma cell phenotype.

\section{Acknowledgments}

We thank Drs. Richard Nordan for providing the T1165 cell line, antiserum to murine IL-6, and for helpful discussions, Frank Lee for the pCD-mIL6 plasmid, Timothy Browder and Neal Epstein for technical advice, Michael Kuehl for the immunoglobulin heavy chain probe, and Glauco Frizzera for reviewing the tissue sections.

This work was supported in part by the Lucille P. Markey Charitable Trust. Dr. Brandt is a Lucille P. Markey Scholar.

\section{References}

1. Kishimoto, T. 1989. The biology of interleukin-6. Blood. 74:1-10.
2. Castell, J. V., M. J. Gomez-Lechon, M. David, T. Hirano, T. Kishimoto, and P. C. Heinrich. 1988. Recombinant human interleukin-6 (IL-6/BSF-2/HSF) regulates the synthesis of acute phase proteins in human hepatocytes. FEBS (Fed. Eur. Biochem. Soc.) Lett. 232:347-350.

3. Prowse, K. R., and H. Baumann. 1989. Interleukin-1 and interleukin-6 stimulate acute-phase protein production in primary mouse hepatocytes. J. Leuk. Biol. 45:55-61.

4. Marinkovic, S., G. P. Jahreis, G. G. Wong, and H. Baumann. 1989. IL-6 modulates the synthesis of a specific set of acute phase plasma proteins in vivo. J. Immunol. 142:808-812.

5. Kikutani, H., T. Taga, S. Akira, H. Kishi, Y. Miki, O. Saiki, Y. Yamamura, and T. Kishimoto. 1985. Effect of B cell differentiation factor (BCDF) on biosynthesis and secretion of immunoglobulin molecules in human B cell lines. J. Immunol. 134:990-995.

6. Muraguchi, A., T. Hirano, B. Tang, T. Matsuda, Y. Horii, K. Nakajima, and T. Kishimoto. 1988. The essential role of B cell stimulatory factor 2 (BSF-2/IL-6) for the terminal differentiation of B cells. J. Exp. Med. 167:332-344.

7. Takai, Y., G. G. Wong, S. C. Clark, S. J. Burakoff, and S. H. Herrmann. 1988. B cell stimulatory factor-2 is involved in the differentiation of cytotoxic T lymphocytes. J. Immunol. 140:508-512.

8. Okada, M., M. Kitahara, S. Kishimoto, T. Matsuda, T. Hirano, and T. Kishimoto. 1988. IL-6/BSF-2 functions as a killer helper factor in the in vitro induction of cytotoxic T cells. J. Immunol. 141:15431549.

9. Ikebuchi, K., G. G. Wong, S. C. Clark, J. N. Ihle, Y. Hirai, and M. Ogawa. 1987. Interleukin 6 enhancement of interleukin 3-dependent proliferation of multipotential hemopoietic progenitors. Proc. Natl. Acad. Sci. USA. 84:9035-9039.

10. Wong, G. G., J. S. Witek-Giannotti, P. A. Temple, R. Kriz, C. Ferenz, R. M. Hewick, S. C. Clark, K. Ikebuchi, and M. Ogawa. 1988. Stimulation of murine hemopoietic colony formation by human IL-6. J. Immunol. 140:3040-3044.

11. Chiu, C.-P., C. Moulds, R. L. Coffman, D. Rennick, and F. Lee. 1988. Multiple biological activities are expressed by a mouse interleukin 6 cDNA clone isolated from bone marrow stromal cells. Proc. Natl. Acad. Sci. USA. 85:7099-7103.

12. Sehgal, P. B., D. C. Helfgott, U. Santhanam, S. B. Tatter, R. H. Clarick, J. Ghrayeb, and L. T. May. 1988. Regulation of the acute phase and immune responses in viral disease. Enhanced expression of the $\beta_{2}$-interferon/hepatocyte-stimulating factor/interleukin-6 gene in virus-infected human fibroblasts. J. Exp. Med. 167:1951-1956.

13. Nakajima, K., O. Martinez-Maza, T. Hirano, E. C. Breen, P. G. Nishanian, J. F. Salazar-Gonzalez, J. L. Fahey, and T. Kishimoto. 1989. Induction of IL-6 (B cell stimulatory factor- $2 / \mathrm{IFN}-\beta_{2}$ ) production by HIV. J. Immunol. 142:531-536.

14. Kohase, M., D. Henriksen-DeStefano, L. T. May, J. Vilcek, and P. B. Sehgal. 1986. Induction of $\beta_{2}$-interferon by tumor necrosis factor: a homeostatic mechanism in the control of cell proliferation. Cell. 45:659-666.

15. Walther, Z., L. T. May, and P. B. Sehgal. 1988. Transcriptional regulation of the interferon- $\beta_{2} / B$ cell differentiation factor $B S F-2 / h e-$ patocyte-stimulating factor gene in human fibroblasts by other cytokines. J. Immunol. 140:974-977.

16. Waage, A., P. Brandtzaeg, A. Halstensen, P. Kierulf, and T. Espevik. 1989. The complex pattern of cytokines in serum from patients with meningococcal septic shock. Association between interleukin 6, interleukin 1, and fatal outcome. J. Exp. Med. 169:333-338.

17. Ueno, Y., N. Takano, H. Kanegane, T. Yokoi, A. Yachie, T. Miyawaki, and N. Taniguchi. 1989. The acute phase nature of interleukin 6: studies in Kawasaki disease and other febrile illnesses. Clin. Exp. Immunol. 76:337-342.

18. Hack, C. E., E. R. De Groot, R. J. F. Felt-Bersma, J. H. Nuijens, R. J. M. Strack Van Schijndel, A. J. M. Eerenberg-Belmer, L. G. Thijs, and L. A. Aarden. 1989. Increased plasma levels of interleukin-6 in sepsis. Blood. 74:1704-1710.

19. Kawano, M., T. Hirano, T. Matsuda, T. Taga, Y. Horii, K. Iwato, H. Asaoku, B. Tang, O. Tanabe, H. Tanaka, A. Kuramoto, and 
T. Kishimoto. 1988. Autocrine generation and requirement of BSF-2/

IL-6 for human multiple myelomas. Nature (Lond.). 332:83-85.

20. Klein, B., X.-G. Zhang, M. Jourdan, J. Content, F. Houssiau, L. Aarden, M. Piechaczyk, and R. Bataille. 1989. Paracrine rather than autocrine regulation of myeloma-cell growth and differentiation by interleukin-6. Blood. 73:517-526.

21. Hoang, T., A. Haman, O. Goncalves, G. G. Wong, and S. C Clark. 1988. Interleukin-6 enhances growth factor-dependent proliferation of the blast cells of acute myeloblastic leukemia. Blood. 72:823826.

22. Yee, C., A. Biondi, X. H. Wang, N. N. Iscove, J. de Sousa, L. A Aarden, G. G. Wong, S. C. Clark, H. A. Messner, and M. D. Minden. 1989. A possible autocrine role for interleukin- 6 in two lymphoma cell lines. Blood. 74:798-804.

23. Miki, S., M. Iwano, Y. Miki, M. Yamamoto, B. Tang, K. Yokokawa, T. Sonoda, T. Hirano, and T. Kishimoto. 1989. Interleukin-6 (IL-6) functions as an in vitro autocrine growth factor in renal cell carcinomas. FEBS (Fed. Eur. Biochem. Soc.) Lett. 250:607-610.

24. Grossman, R. M., J. Krueger, D. Yourish, A. Granelli-Piperno D. P. Murphy, L. T. May, T. S. Kupper, P. B. Sehgal, and A. B. Gottlieb. 1989. Interleukin 6 is expressed in high levels in psoriatic skin and stimulates proliferation of cultured human keratinocytes. Proc. Natl. Acad. Sci. USA. 86:6367-6371.

25. Horii, Y., A. Muraguchi, M. Iwano, T. Matsuda, T. Hirayama, H. Yamada, Y. Fujii, K. Dohi, H. Ishikawa, Y. Ohmoto, K. Yoshizaki, T. Hirano, and T. Kishimoto. 1989. Involvement of IL-6 in mesangial proliferative glomerulonephritis. J. Immunol. 143:3949-3955.

26. Houssiau, F. A., J.-P. Devogelaer, J. Van Damme, C. Nagant de Deuxchaisnes, and J. Van Snick. 1988. Interleukin-6 in synovial fluid and serum of patients with rheumatoid arthritis and other inflammatory arthritides. Arthritis Rheum. 31:784-788.

27. Hirano, T., T. Matsuda, M. Tucker, N. Miyasaka, G. Buchan, B. Tang, K. Sato, M. Shimizu, R. Maini, M. Feldmann, and T. Kishimoto. 1988. Excessive production of interleukin 6/B cell stimulatory factor-2 in rheumatoid arthritis. Eur. J. Immunol. 18:1797-1801.

28. Guerne, P.-A., B. L. Zuraw, J. H. Vaughan, D. A. Carson, and M. Lotz. 1989. Synovium as a source of interleukin 6 in vitro. Contribution to local and systemic manifestations of arthritis. J. Clin. Invest. 83:585-592.

29. Yoshizaki, K., T. Matsuda, N. Nishimoto, T. Kuritani, L. Taeho, K. Aozasa, T. Nakahata, H. Kawai, H. Tagoh, T. Komori, S. Kishimoto, T. Hirano, and T. Kishimoto. 1989. Pathogenic signifcance of interleukin-6 (IL-6/BSF-2) in Castleman's disease. Blood. 74:1360-1367.

30. Hirano, T., T. Taga, K. Yasukawa, K. Nakajima, N. Nakano, F. Takatsuki, M. Shimizu, A. Murashima, S. Tsunasawa, F. Sakiyama, and T. Kishimoto. 1987. Human B-cell differentiation factor defined by an antipeptide antibody and its possible role in autoantibody production. Proc. Natl. Acad. Sci. USA. 84:228-231.

31. Nordan, R. P., and M. Potter. 1986. A macrophage-derived factor required by plasmacytomas for survival and proliferation in vitro. Science (Wash. DC). 233:566-569.

32. Mann, R., R. C. Mulligan, and D. Baltimore. 1983. Construction of a retrovirus packaging mutant and its use to produce helper-free defective retrovirus. Cell. 33:153-159.

33. Miller, A. D., and C. Buttimore. 1986. Redesign of retrovirus packaging cell lines to avoid recombination leading to helper virus production. Mol. Cell. Biol. 6:2895-2902.

34. Yokota, T., F. Lee, D. Rennick, C. Hall, N. Arai, T. Mosmann G. Nabel, H. Cantor, and K.-I. Arai. 1984. Isolation and characterization of a mouse cDNA clone that expresses mast-cell growth-factor activity in monkey cells. Proc. Natl. Acad. Sci. USA. 81:1070-1074.

35. Armentano, D., S.-F. Yu, P. W. Kantoff, T. von Ruden, W. F. Anderson, and E. Gilboa. 1987. Effect of internal viral sequences on the utility of retroviral vectors. J. Virol. 61:1647-1650.

36. Graham, F. L., and A. J. van der Eb. 1973. A new technique for the assay of infectivity of human adenovirus 5 DNA. Virology. 52:456-467.

37. Bassin, R. H., N. Tuttle, and P. J. Fischinger. 1971. Rapid cell culture technique for murine leukemia viruses. Nature (Lond.). 229:564-566.

38. Whitney, J. B., III. 1978. Simplified typing of mouse hemoglobin $(\mathrm{Hbb})$ phenotypes using cystamine. Biochem. Genet. 16:667-672.

39. Maniatis, T., E. F. Fritsch, and J. Sambrook. 1982. Molecular Cloning. A Laboratory Manual. Cold Spring Harbor Laboratory, New York

40. Chirgwin, J. M., A. E. Przybyla, R. J. MacDonald, and W. J. Rutter. 1979. Isolation of biologically active ribonucleic acid from sources enriched in ribonuclease. Biochemistry. 18:5294-5299.

41. Feinberg, A. P., and B. Vogelstein. 1983. A technique for radiolabeling DNA restriction endonuclease fragments to high specific activity. Anal. Biochem. 132:6-13.

42. Wong, P. M. C., S.-W. Chung, and A. W. Nienhuis. 1987. Retroviral transfer and expression of the interleukin-3 gene in hemopoietic cells. Genes Dev. 1:358-365.

43. Castleman, B., L. Iverson, and V. P. Menendez. 1956. Localized mediastinal lymph-node hyperplasia resembling thymoma. Cancer. 9:822-830.

44. Frizzera, G. 1988. Castleman's disease and related disorders. Semin. Diag. Pathol. 5:346-364.

45. Frizzera, G., B. A. Peterson, E. D. Bayrd, and A. Goldman. 1985. A systemic lymphoproliferative disorder with morphologic features of Castleman's disease: clinical findings and clinicopathologic correlations in 15 patients. J. Clin. Oncol. 3:1202-1216.

46. Frizzera, G., P. M. Banks, G. Massarelli, and J. Rosai. 1983. A systemic lymphoproliferative disorder with morphologic features of Castleman's disease. Pathological findings in 15 patients. Am. J. Surg. Pathol. 7:211-231.

47. Lee, S. L., F. Rosner, I. Rivero, F. Feldman, and A. Hurwitz. 1965. Refractory anemia with abnormal iron metabolism. Its remission after resection of hyperplastic mediastinal lymph nodes. $N$. Engl. J. Med. 272:761-766.

48. Koike, K., T. Nakahata, M. Takagi, T. Kobayashi, A. Ishiguro, K. Tsuji, K. Naganuma, A. Okano, Y. Akiyama, and T. Akabane. 1988. Synergism of BSF-2/interleukin 6 and interleukin 3 on development of multipotential hemopoietic progenitors in serum-free culture. J. Exp. Med. 168:879-890.

49. Ishibashi, T., H. Kimura, T. Uchida, S. Kariyone, P. Friese, and S. A. Burstein. 1989. Human interleukin 6 is a direct promoter of maturation of megakaryocytes in vitro. Proc. Natl. Acad. Sci. USA. 86:5953-5957.

50. Ishibashi, T., H. Kimura, Y. Shikama, T. Uchida, S. Kariyone, T. Hirano, T. Kishimoto, F. Takatsuki, and Y. Akiyama. 1989. Interleukin-6 is a potent thrombopoietic factor in vivo in mice. Blood. 74:1241-1244.

51. Suematsu, S., T. Matsuda, K. Aozasa, S. Akira, N. Nakano, S. Ohno, J.-I. Miyazaki, K.-I. Yamamura, T. Hirano, and T. Kishimoto. 1989. IgGl plasmacytosis in interleukin 6 transgenic mice. Proc. Natl. Acad. Sci. USA. 86:7547-7551.

52. Hanson, C. A., G. Frizzera, D. F. Patton, B. A. Peterson, K. L. McClain, K. J. Gajl-Peczalska, and J. H. Kersey. 1988. Clonal rearrangement for immunoglobulin and T-cell receptor genes in systemic Castleman's disease. Association with Epstein-Barr virus. Am. J. Pathol. 131:84-91.

53. Nagai, M., S. Irino, H. Uda, T. Ohtsu, K. Tobinai, and M. Shimoyama. 1988. Molecular genetic and immunohistochemical analyses of a case of multicentric Castleman's disease. Jpn. J. Clin. Oncol. 18:149-157.

54. Mushinski, J. F. 1988. c-myc oncogene activation and chromosomal translocation in BALB/c plasmacytomas. In Cellular Oncogene Activation. G. Klein, editor. Marcel Dekker, New York. 181-222. 